\title{
Does this elderly patient have iron deficiency anaemia, and what is the underlying cause?
}

\author{
O M P Jolobe
}

\begin{abstract}
Important implications for the recognition of iron deficiency anaemia include diagnosis and correction of underlying causes, most of which are identifiable, in the older patient, by means of conventional upper gastrointestinal endoscopy, and by colonoscopy. The aetiological search may, however, have to be widened to include enteroscopic examination of the jejunum and ileum and, in some instances, investigation of potential non-gastrointestinal foci of chronic blood loss. A substantial minority may defy even the most thorough search for the underlying cause. (Postgrad Med F 2000;76:195-198)
\end{abstract}

Keywords: iron deficiency; validation; underlying causes

Fundamental to the correct management of iron deficiency is accurate validation of the diagnosis, followed by identification of the underlying cause, hence the requirement for tests of iron status to combine high degrees of sensitivity with comparable degrees of specificity, because "further identification of the cause of depletion or iron stores is bound to result in tedious clinical and laboratory investigation". ${ }^{1}$

\section{Definition}

Iron deficiency is the outcome of a long period of negative iron balance, culminating in exhaustion of the body's iron stores. However, it is only when the haemoglobin concentration falls below the lower limit of the normal range (that is $<120 \mathrm{~g} / 1$ and $<130 \mathrm{~g} / 1$ in elderly females and males, respectively), ${ }^{2}$ that the patient can be fully designated as having progressed to the status of iron deficiency anaemia. ${ }^{3}$

\section{Prevalence in the elderly}

Iron deficiency has a documented prevalence of $4 \%-7 \%$ among North American men and women aged $>70$, the corresponding prevalence of anaemia resulting from this haematinic deficiency being $2 \%$ in this age group, using haemoglobin cut off concentrations of $118 \mathrm{~g} / 1$ and $124 \mathrm{~g} / 1$ for female and males respectively. ${ }^{4}$ In a community survey of men and women aged $>70$, iron deficiency anaemia outranked the anaemia of chronic disorders in prevalence, ${ }^{5}$ but the reverse was shown to be the case in patients aged $>65$, encountered in hospital practice. ${ }^{6}$
Validation of iron deficiency

Although absence of stainable bone marrow iron is regarded as the definitive marker of iron deficiency, ${ }^{6}$ this may not be an infallible criterion, given the disparity in stainable iron between needle biopsy sections and simultaneously aspirated smears, hence the recommendation, not only to aspirate generous amounts of stroma, but also to confirm the findings, where possible, by marrow biopsy. ${ }^{7}$

Validation by hypoferritinaemia is the alternative strategy, ${ }^{5}$ the cut off concentration recommended by the World Health Organisation committee of experts being $12 \mu \mathrm{g} / 1,{ }^{8}$ coinciding with the concentration proposed by Lipschitz et $a l$, on the basis of their analysis of 250 hospitalised patients with anaemia and/or disorders of iron metabolism. ${ }^{9}$ Due to the capacity for serum ferritin also to behave as an acute phase protein, the coexistence of iron deficiency and various inflammatory disorders (including chronic renal disease and liver disease, respectively) may be associated with normal concentrations of serum ferritin, ${ }^{10}$ necessitating the use of other diagnostic parameters (apart from bone marrow aspiration and/or biopsy) for validation of this haematinic deficiency. One such parameter is the likelihood ratio derived from the true positive compared with the false positive rate for iron deficiency at a given level for serum ferritin, one outcome being a $>95 \%$ probability of iron deficiency in elderly patients with serum ferritin $<18$ $\mu \mathrm{g} / \mathrm{l} .{ }^{11} \mathrm{~A}$ more recent development utilises evaluation of serum transferrin receptor (TfR) concentrations, which increase in direct proportion with amounts of TfR expressed on erythroid precursors, in order to enable the latter to compete more successfully for diminishing tissue concentrations of iron during the evolution of the iron deficiency state. When combined with logarithmic transformation of the serum ferritin level (log ferritin), in order to generate a parameter designated as TfR/log ferritin (TfR-F index), a reliable separation can be achieved between subjects characterised by coexistence of iron deficiency and anaemia of chronic disorders compared with those with the sole diagnosis of anaemia of chronic disorders. ${ }^{1}$ The strongest circumstantial evidence for iron deficiency anaemia is an increase in haemoglobin by $>20 \mathrm{~g} / 1$ after three weeks of iron replacement therapy. ${ }^{12}$ Documentation of clinical stigmata of iron deficiency is also highly suggestive, with due regard for the fact that koilonychia can also occur after exposure to caustic agents, while atrophic glossitis and angular stomatitis may
Submitted 24 February 1999 Accepted 7 June 1999 
Box 1: Differential diagnosis of microcytic hypochromic anaemia

- Iron deficiency anaemia

- Anaemia of chronic disorders

- Thalassaemia

- Sideroblastic anaemia

also feature in megaloblastic deficiency and riboflavin deficiency, respectively. ${ }^{3}$

\section{Haematological manifestations}

Although iron deficiency is typically characterised by mean corpuscular volume (MCV) and mean corpuscular haemoglobin $(\mathrm{MCH})$ concentrations of $<80 \mathrm{fl}$ and $<26 \mathrm{pg}$, respectively, ${ }^{13}$ it is a matter of controversy which one of the two parameters has greater predictive value. ${ }^{7}$ Comparable changes in $\mathrm{MCV}$ and $\mathrm{MCH}$ occur in anaemia associated with sepsis, chronic inflammation, malignancy, chronic renal disease, ${ }^{1014} 15$ and even in liver cirrhosis, ${ }^{16}$ and also in thalassaemia and sideroblastic anaemia, respectively (box 1). ${ }^{77}$ Thrombocytosis is another haematological manifestation of iron deficiency, documented even in the absence of acute bleeding, ${ }^{18}$ and the fact that it may also occur in iron replete subjects with anaemia of chronic disorders ${ }^{19}$ adds to the diagnostic confusion between the two disorders. In the latter context, the coexistence of thrombocytosis and impairment of haemoglobinisation of red blood cells is attributable to the role of cytokines in thrombopoiesis, and in mobilisation of iron from reticuloendothelial macrophages. $^{20}$

\section{Underlying causes of iron deficiency}

The under investigation of iron deficiency anaemia is exemplified by a study showing that, in one health district, gastrointestinal investigations for the underlying cause of this haematinic deficiency were performed in only $63 \%$ of 109 iron deficient patients aged $>50,{ }^{21}$ notwithstanding the age related prevalence of gastrointestinal causes of this disorder. The intuitive expectation that the underlying cause will be

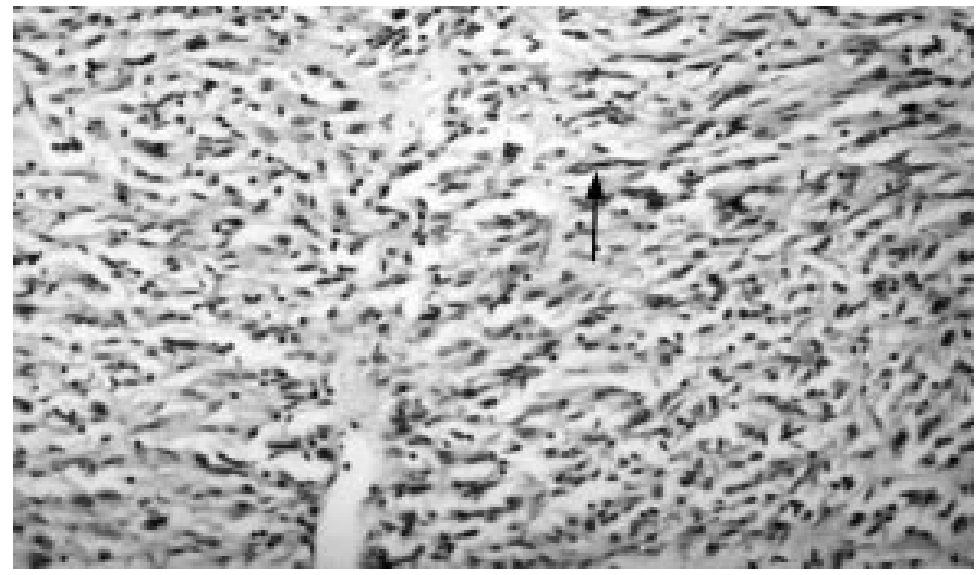

Figure 1 Histological representation of spindle shaped cells (arrowed) of a small bowel malignant stromal tumour (haematoxylin and eosin $\times 200$ ) diagnosed only at necropsy, in an 88 year old woman with a three year history of iron deficiency anaemia, requiring frequent blood transfusions when iron replacement therapy proved inadequate for maintaining normal haemoglobin concentrations.

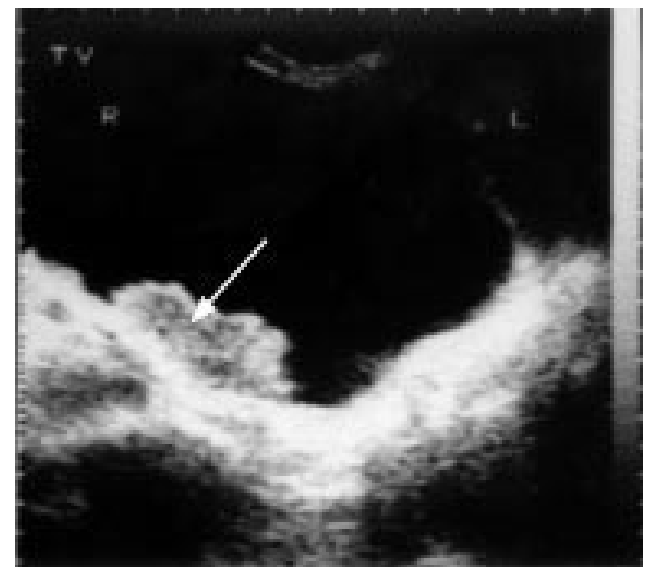

Figure 2 Ultrasonographic representation of a bladder tumour (arrowed) in a 73 year old man presenting with iron deficiency anaemia and haematuria.

disclosed by systematic analysis of symptoms and signs ${ }^{17}$ has to be tempered with the recognition that, even in the absence of symptoms, as many as $44 \%$ of adults with iron deficient anaemia will harbour gastrointestinal lesions capable of causing chronic blood loss. ${ }^{22}$ When symptoms are present, the positive predictive value for upper gastrointestinal tract lesions (range 18\%-86\%, median 60\%), can be almost twice as high as it is for lower gastrointestinal tract pathology (range $28 \%-52 \%$, median $35 \%){ }^{23-28}$ This might be a reflection of the fact that an analysis of 1207 patients compiled from 10 studies, each enrolling $>70$ patients for the purpose of identifying underlying causes of iron deficiency anaemia and/or occult gastrointestinal bleeding, yielded a ratio of $491 v 283$ for patients with upper $v$ lower gastrointestinal tract lesions, both sites being simultaneously involved in approximately 104 instances. ${ }^{23-32}$ In another analysis, comprising 721 iron-deficient subjects aged $>50$, compiled from seven studies, upper gastrointestinal lesions were documented twice as frequently as those from the lower gastrointestinal tract. ${ }^{33}$ However, in view of higher prevalence of malignancy in lower as opposed to upper gastrointestinal tract lesions, iron deficient patients aged $>50$, including those with benign upper gastrointestinal lesions, should almost always be offered colonoscopy because it is in this age group that malignant colorectal pathology may coexist with benign lesions of the upper gastrointestinal tract. ${ }^{33}$ When this strategy was put to the test in a prospective study of 89 patients of mean age 65,26 patients were found to have lesions in both the upper and lower gastrointestinal tract. So thorough were the investigators that as many as 14 of their subjects were subjected to small bowel barium enema studies as well. ${ }^{31}$ The principle that identification of small bowel pathology should be part of the overall strategy for investigation of iron deficiency anaemia is one which is being increasingly acknowledged, enteroscopy, ${ }^{34}$ small bowel enema (enteroclysis), ${ }^{35}$ and computer tomographic enteroclysis ${ }^{36}$ being just three of the expanding list of modalities aiming to ensure that the mistake of overlooking the existence of tumours of the small bowel (fig 1) should occur 


\section{Questions}

(1) Is the diagnosis of iron deficiency anaemia tenable in the presence of a normal serum ferritin concentration?

(2) What is the physiological basis for evaluation of serum transferrin receptor levels in iron deficiency, and how can this parameter augment the usefulness of the serum ferritin in patients with microcytic hypochromic anaemia?

(3) How reliable are gastrointestinal symptoms in predicting the site of gastrointestinal blood loss?

(4) How reliable are faecal occult blood tests in distinguishing between upper and lower gastrointestinal bleeding?

(5) What is the rationale for colonoscopy in the majority of iron deficient patients aged $>50$, in spite of identification of non-malignant causes of upper gastrointestinal bleeding?

(6) What are the three most striking features of coeliac disease that you have discovered from this presentation?

\section{Answers}

(1) Yes. When iron deficiency coexists with the anaemia of chronic disorders, the behaviour of serum ferritin as an acute phase reactant counteracts the expected fall in serum ferritin, leading to "false normalisation" of this parameter.

(2) During evolution of the iron deficient state, circulating levels of transferrin receptor (TfR), and amounts of this substance expressed on the surface of erythroid precursors, undergo an increase, in response to diminishing tissue levels of iron. The ratio of $\mathrm{TfR} / \log$ ferritin appears to provide a clear separation between coexisting iron deficiency and anaemia of chronic disorders compared with anaemia of chronic disorders as the sole diagnosis.

(3) Symptomatology has poor site specificity.

(4) Faecal occult blood tests also have poor site specificity.

(5) Although upper gastrointestinal tract lesions are the ones most commonly encountered in iron deficiency, and are also more likely to be benign than malignant, colonic lesions, though less frequent, are more likely to be malignant, and may coexist with benign upper gastrointestinal tract lesions.

(6) Iron deficiency anaemia is the commonest extraintestinal manifestation of coeliac disease; patients aged $>60$ comprise up to $19 \%$ of the adult coeliac population; positive tests for faecal occult blood may occur in up to $47 \%$ of adults with coeliac disease. isting vitamin $B_{12}$ malabsorption being a feature in a subgroup of seven. ${ }^{39}$ It is also just as important to be aware of the fact that, when the two haematinic deficiencies coexist, the microcytic hypochromic haematological profile may totally disguise the presence of vitamin $B_{12}$ deficiency, ${ }^{40}$ the only occasional clue being intercurrent thrombocytopenia. Thrombocytopenia itself, however, may be a rare manifestation of iron deficiency anaemia. ${ }^{41}$ Diverticular disease of the colon is not a recognised cause of iron deficiency, ${ }^{29}{ }^{32}$ and it has the potential to be diagnostically misleading when, on barium enema, it gives the impression of being the sole diagnosis, coexisting colonic carcinoma being detectable only by subsequent colonoscopy. ${ }^{42}$ Even after intensive investigation, as many as $40 \%$ of patients aged $>50$ may have no identifiable underlying cause of iron deficiency. ${ }^{33}$ Follow up averaging 39 months in 69 such patients did not disclose any malignant lesions on follow up colonoscopy, and the anaemia itself resolved in $71 \% .{ }^{43}$ One patient, subsequently found to have duodenal angiodysplasia, had iron deficiency sufficiently severe to require intermittent blood transfusion, and most of the rest appeared to have coexisting anaemia of chronic disorders.

The final issue is that of sensitivity and site specificity of tests for faecal occult blood in suspected chronic gastrointestinal blood loss. Sensitivities are down to a mere $50 \%-55 \%,{ }^{25} 26$ with positive predictive values of $17 \%-43 \%$, and $16 \%-26 \%$, for upper and lower gastrointestinal lesions, respectively. ${ }^{25} 273244$ Positive tests discriminate poorly between upper and lower gastrointestinal lesions, as shown by two studies comprising 119 and 134 patients, respectively, $17 \%-59.6 \%$ of whom harboured upper gastrointestinal tract lesions, colorectal pathology being a feature in $16 \%-45 \%$. Five to 10 per cent had lesions at both sites. ${ }^{32}{ }^{45}$ Even when colonoscopic investigation is entirely negative, as many as $37 \%$ of faecal occult blood positive patients prove to have upper gastrointestinal sources of chronic blood loss. ${ }^{44}$ In the final analysis, success is very limited in the prediction of site of chronic gastrointestinal blood loss through the use of standardised questionnaires and/or faecal occult blood tests, as shown by the prospective study of 80 iron deficient patients of mean age 70 (range 37-91), in whom significant lesions occurred at either the upper or the lower gastrointestinal tract, regardless of the presence or absence of symptoms, or faecal occult blood status. ${ }^{46}$ Even in coeliac disease, up to $47 \%$ of adults may have positive faecal occult blood tests. ${ }^{47}$ frequent extraintestinal manifestation of this disorder, ${ }^{37}$ and that patients aged $>60$ comprise up to $19 \%$ of the adult coeliac population. ${ }^{38}$

Dietary deficiency, when specifically sought, may be the sole cause of iron deficiency anaemia in as few as $5 \%$ of elderly patients subsisting on a Western diet. ${ }^{24}$ The recognition is equally important that hypochlorhydria (typically associated with autoimmune gastritis) may impair the bioavailability of dietary iron, with consequent iron deficiency anaemia, as in 22 patients reported with histamine fast achlohydria and parietal cell antibodies, coexMy thanks to Dr G R Dixon MRCPath, Consultant Pathologist
at Tameside General Hospital for the necropsy report and subat Tameside General Hospital for the necropsy report and sub-
sequent photomicrograph relating to figure 1 . I am indebted to sequent photomicrograph relating to figure 1 . I am in
Mrs A Russell for the preparation of this manuscript.

1 Punnonen K, Irjala K, Rajamaki A. Serum transferrin receptor and its ratio to serum ferritin in the diagnosis of iron deficiency. Blood 1997;89:1052-7.

2 Izaks GJ, Westendorf RGJ, Knook DL. The definition of anemia in older persons. FAMA 1999;281:1714-17. GR, Bithell TC, Forester J, et al, eds. Wintrobe's clinical haematology. 9th Ed, volume 1. Philadelphia: Lea and Febiger, 1993 (chapter 26).
3 Lee GR. Iron deficiency and iron-deficient anemia. In: Lee 
4 Looker AC, Dallman PR, Carroll MD, et al. Prevalence of iron deficiency in the United States. $\mathcal{F A M A} 1997 ; 277: 973-6$ 5 Nilsson H, Jagenburg R, Landahl S, et al. Haematologica abnormalities and reference intervals in the elderly. Acto Med Scand 1988:224:595-604.

6 Joosten E, Pelemans W, Hiele M, et al. Prevalence and causes of anaemia in a geriatric hospitalised population. Gerontology 1992

7 Cook JD. Clinical evaluation of iron deficiency. Semin Hematol 1982;19:6-18.

8 World Health Organisation Group of Experts. Nutritional anaemias. WHO technical report series No 503. Geneva: WHO, 1972

9 Lipschitz DA, Cook JD, Finch CA. A clinical evaluation of serum ferritin as an index of iron stores. N Engl f Med 1974; 290:1213-1216.

10 Sears DA. Anemia of chronic disease. Med Clin North Am 1992;76:567-79.

11 Guyatt GH, Patterson C, Ali M, et al. Diagnosis of iron-deficiency anemia in the elderly. Am $\mathcal{F}$ Med 1990;88: 205-9.

12 Coleman DG, Stevens AR, Finch CA. The treatment of iron deficiency anemia. Blood 1955;10:567-81.

13 Bainton DF, Finch CA. The diagnosis of iron deficiency anemia. Am f Med 1964;37:62-70.

14 Kurer SB, Seifert B, Michel B, et al. Prediction of iron deficiency in chronic inflammatory rheumatic disease anaemia Br f Haematol 1995;91:820-6.

15 Drueke TB, Barany P, Cazzola M, et al. Management of iron deficiency in renal anemia: guidelines for the optimal therapeutic approach in erythropoietin-treated patients. Clin Nephrol 1997;48:1-8.

16 Intragumtorchai T, Rojnukkarin P, Swasdikul D, et al. The role of ferritin in the diagnosis of iron deficiency anaemia in patients with liver circhosis. F Intern Med 1998;243.233-41.

17 patients De Gruchy GC. Blo I loss anaemia. Iron deficiency. Hypochromic anaemia. In: Pennington D, Rush B, Castald , eds. Clinical haematology in medical practice. 4th Ed.

18 Gross S, Keefer V, Newman AS. The platelets in iron deficiency anemia. 1 . The response to oral and parenteral iron. ciency anemia. 1. The respon

19 Cohen H, Machin SJ. Platelet abnormalities. In: Delamore IW, Lin Yin JA, eds. Haematological aspects of systemic disease. London: Bailliere Tindall, 1990 (chapter 6)

20 Grabay C, Kushner I. Acute phase proteins and other systemic responses to inflammation. $N$ Engl $f \mathrm{Med}$ 1999;340:448-54

21 Lucas CA, Logan ECM, Logan HFA. Audit of the investigation and outcome of iron deficiency anaemia in one health district. $\mathcal{F} R$ Coll Physicians Lond 1996;30:33-5.

22 Wilcox CM, Alexander LN, Clark S. Prospective evaluation of the gastrointestinal tract in patient with iron deficiency and no systemic or gastrointestinal symptoms or signs. $A m \mathcal{F}$ Med 1997;103:405-9.

23 McIntyre AS, Long RG. Prospective survey of investigations in outpatients referred with iron deficiency anaemia. Gut in outpatients ref

24 Cook IJ, Pavli P, Riley JW, et al. Gastrointestinal investigation of iron deficiency anaemia. BMF 1986;292:1380-2.

25 Gordon SR, Smith RE, Power GC. The role of endoscopy in the evaluation of iron deficiency anemia in patients over the the evaluation of iron deficiency anemia in patien

26 Kepczyk T, Kadakia SC. Prospective evaluation of gastrointestinal tract in patients with iron-deficiency anemia. Dig Dis Sci 1995;40:1283-9.
27 Zuckerman G, Benitez J. A prospective study of bidirectional endoscopy (colonoscopy and upper endoscopy) in the evaluation of patients with occult gastrointestinal bleeding. Am 7 Gastroenterol 1992;87:62-6.

28 Lee JG, Sahagun G, Oehlke MA, et al. Serious gastrointestinal pathology found in patients with serum ferritin values of <50 ng/ml. Am f Gastroenterol 1998;93: 772-6.

29 Rockey DC, Cello JP. Evaluation of the gastrointestinal tract in patients with iron deficiency anemia. N Engl F Med 1993; 329:1691-5.

30 Kerlin $\mathrm{P}$, Reiner $\mathrm{R}$, Davies $\mathrm{M}$, et al. Iron deficiency anaemia-a prospective study. Aust N Z f Med 1979;9:402-

31 Hardwick RH, Armstrong CP. Synchronous upper and lower gastrointestinal endoscopy is an effective method of investigating iron-deficiency anaemia. Br f Surg 1997;84: 1725-8.

32 Alamayehu G, Jarnerot G. Same-day upper and lower endoscopy in patients with occult bleeding, melena, hematochezia, and/or microcytic anemia. Scand f Gastroenterol 1993;28:667-72.

33 Fireman Z, Kopelman Y, Sternberg A. Endoscopic evaluation of iron deficiency anemia and follow-up in patients older than age 50. 7 Clin Gastroenterol 1998;26:7-10.

34 Chak A, Cooper GS, Canto MI, et al. Enteroscopy for initial evaluation of iron deficiency. Gastrointest Endosc 1998;47: $144-8$

35 Maglinte DDT, Reyes BL. Small bowel cancer. Radiologic techniques. Radiol Clin North Am 1997;35:361-80.

36 Bender GN, Maglinte DDT, Kloppel Von R, et al. CT enteroclysis: a superficial diagnostic procedure or valuable when investigating small-bowel disease? $A f R A m$ f Roentgenol 1999;172:373-8.

37 Bottaro G, Cataldo F, Rotolo N, et al. The clinical pattern of subclinical/silent celiac disease: an analysis on 1026 consecutive cases. Am f Gastoenterol 1999;94:691-6.

38 Hankey GL, Holmes GKT. Coeliac disease in the elderly. Gut 1994;35:65-7.

39 Dagg JH, Goldberg A, Gibbs WN, et al. Detection of latent pernicious anaemia in iron-deficiency anaemia. BMF 1966; iii: $619-21$.

40 Jolobe OMP. Subnormal vitamin $\mathrm{B}_{12}$ concentration (letter). 7 Am Geriatr Soc 1997;45:1158.

41 Berger M, Brass LF. Severe thrombocytopenia in iron deficiency anemia. Am f Hematol 1987;24:425-8.

42 Lindsay DC, Freeman JG, Cobden I, et al. Should colonoscopy be the first investigation for colonic disease? BMF 1988:296:167-9.

43 Gordon S, Bensen S, Smith R. Long-term follow up of older patients with iron deficiency anemia after negative GI evaluation. Am $\mathcal{F}$ Gastroenterol 1996;91:885-9.

44 Hsia PC, Al-Kawas FH. Yield of upper endoscopy in evaluation of asymptomatic patients with hemoccult-positive stool after a negative colonoscopy. Am f Gastroenterol 1992; 87:1571-4.

45 Rockey DC, Koch J, Cello JP, et al. Relative frequency of upper gastrointestinal and colonic lesions in patients with positive fecal occult blood tests. $N$ Engl f Med 1998;339: 153-9.

46 Bampton PA, Holloway RH. A prospective study of gastroenterological causes of iron deficiency anaemia in a general enterological causes of iron deficiency an
hospital. Aust NZ $\mathcal{H}$ Med 1996;26:793-9.

47 Fine KD. The prevalence of occult gastrointestinal bleeding in celiac sprue. $N$ Engl f Med 1996;334:1163-7. 